\title{
The use, integration and perceived value of performance analysis to professional and amateur Irish coaches
}

\author{
Denise Martin \\ Technological University Dublin, denise.martin@tudublin.ie \\ Alan Swanton \\ Sport Ireland Institute \\ Jonathan Bradley \\ Institute of Technology, Carlow
}

See next page for additional authors

Follow this and additional works at: https://arrow.tudublin.ie/ittsciart

Part of the Medicine and Health Sciences Commons

\section{Recommended Citation}

Martin, D., Swanton, A., Bradley, J., \& McGrath, D. (2018). The use, integration and perceived value of performance analysis to professional and amateur Irish coaches. International Journal of Sports Science \& Coaching, 13(4), 520-532. DOI: 10.1177/1747954117753806

This Article is brought to you for free and open access by the School of Science and Computing at ARROW@TU Dublin. It has been accepted for inclusion in Articles by an authorized administrator of ARROW@TU Dublin. For more information, please contact arrow.admin@tudublin.ie, aisling.coyne@tudublin.ie, gerard.connolly@tudublin.ie.

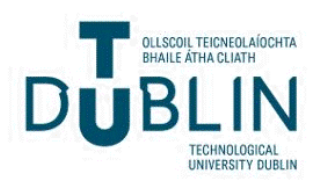




\section{Authors}

Denise Martin, Alan Swanton, Jonathan Bradley, and Denise McGrath 


\title{
The use, integration and perceived value of performance analysis to professional and amateur Irish coaches
}

International Journal of Sports Science \& Coaching

2018, Vol. 13(4) 520-532

(C) The Author(s) 2018

Reprints and permissions:

sagepub.co.uk/journalsPermissions.nav

DOI: 10.1 |77/I747954| |7753806

journals.sagepub.com/home/spo

(SAGE

\author{
Denise Martin ${ }^{1,2}$, Alan Swanton ${ }^{3}$, Jonathan Bradley ${ }^{4}$ and \\ Denise McGrath'
}

\begin{abstract}
Research into the perceptions, practices and engagement of coaches with performance analysis is fundamental to informing the continued development of the discipline and its practitioners. The aim of this study was to survey a large sample of coaches of varying profiles, regarding their use and integration of performance analysis, to explore its perceived value and barriers to its use. Survey data were analysed from 538 Irish coaches qualified at Level I and above ( $82 \%$ male), from 37 sports. A spectrum of coaches' engagement with performance analysis, ranging from no formal performance analysis (49\%), to coaches doing their own analysis (coach-as-analyst, 38\%) and coaches with analystsupport (13\%) was observed. The Level 2 coaching qualification was a key distinguisher between coaches using and not using performance analysis. Significant differences exist between the practices of coaches with and without analystsupport. Coaches with analyst-support are more likely to have regular access to video, spend more time analysing, regularly use performance analysis to inform training and use computerised analysis software. Barriers to the use of performance analysis varied along the spectrum of performance analysis engagement. This research can underpin future developments in coach and analyst education that will optimise the systematic use of PA across all levels of sports performance.
\end{abstract}

\section{Keywords}

Coaching process, coach qualifications, notational analysis

\section{Introduction}

Observation and analysis were placed firmly at the heart of the coaching process by Franks et al. ${ }^{1}$ Since then, the need for systematic analysis of sport has led to the emergence of the discipline of performance analysis (PA). PA has been defined as the systematic and objective observation of actual sports performance in order to inform the coaching process. $^{2}$ While PA has been widely adopted by coaches at all levels, ${ }^{3}$ the precise nature of coaches' interactions with PA is currently unknown. For example, it is not clear what characterises coaches who actually use PA, or how access to analyst-support changes coaching practice. The evolution of the PA discipline has brought forth a new professional: the applied performance analyst, a practitioner who works to inform the coach's decision making process. ${ }^{4}$ Real world research into the perceptions, practices and engagement of coaches with PA is fundamental to informing the continued development of the discipline and its practitioners. ${ }^{5}$
Investigations into coach and athlete perceptions of PA have concentrated mainly on elite sport and known users of PA. Several single subject case studies $^{6-9}$ have provided rich insight and analysis of the motivations of elite coaches in using PA, the reality of their practice and how it is received by elite athletes. Broader investigations have examined the perceptions and practices around PA of elite soccer coaches,

Reviewer: Ryan Groom (Manchester Metropolitan University, UK)

'School of Business, Institute of Technology Blanchardstown, Dublin, Ireland

${ }^{2}$ School of Public Health, Physiotherapy and Sports Science, University College Dublin, Dublin, Ireland

${ }^{3}$ Sport Ireland Institute, Dublin, Ireland

${ }^{4}$ Department of Sport, Media and Marketing, IT Carlow, Co. Carlow, Ireland

Corresponding author:

Denise Martin, Institute of Technology Blanchardstown, Blanchardstown Road North, Dublin 15, Ireland.

Email: denise.martin@itb.ie 
players and analysts, ${ }^{10-13}$ elite rugby players, ${ }^{14}$ elite swimming coaches ${ }^{15}$ and recreational badminton coaches. ${ }^{16}$ The only multi-sport survey undertaken by Wright, Atkins and Jones, ${ }^{17}$ investigated how PA tools were used by 46 professional and semi-professional coaches, known to be using PA, and working in hockey, soccer, basketball, rugby league and union. The extent to which coaches in general engage with PA is not known, nor are the factors associated with PA use. Identification of such factors can facilitate a much greater understanding of profiles of coaches using PA and their potential needs.

It has proven difficult to quantitatively determine the impact that PA alone has on sports performance ${ }^{18,19}$ as there are a myriad of other factors at play, such as the quality of opposition, the importance of the competition, home advantage and so on. ${ }^{20}$ Research examining coaches' opinions of PA using interviews or surveys can act as a surrogate measure of the value of PA. Generally, studies have reported that the coaches' perceptions of PA are positive. ${ }^{11,13}$ Wright and colleagues ${ }^{, 17}$ survey of $46 \mathrm{semi} /$ professional coaches found that $91 \%$ valued PA as important or essential to their coaching practice; however, they reported that the coaches felt their National Governing Bodies valued PA considerably less $(59 \%)$. Our study will investigate this in an Irish context across a significantly larger cohort of coaches.

Video feedback has been employed by coaches aiming to improve athlete performance through facilitating learning, changing behaviour, improving efficacy and increasing motivation. ${ }^{21}$ As the delivery of feedback is fundamental to the effectiveness of PA, the perceptions of athletes and coaches $7,8,10,13,14,22$ and the intricacies of the video feedback process itself have been investigated. ${ }^{6,21,23,24}$ It is difficult to try to evaluate the extent of integration of PA into coaching practices as every coach and coaching context is unique. Wright and colleagues ${ }^{17}$ used several metrics as a guide to judge the degree to which PA was systematically integrated into professional and semiprofessional coaching practices. These metrics can be directly aligned to Franks et al.'s ${ }^{1}$ model of the coaching process and included; the use of a PA tool to assist observation, regular access to video, considerable time spent reviewing and analysing, the use of statistics to catalogue performance and the use of PA to inform planning and training on a regular basis. Models of systematic integration of PA described in soccer, rugby and netball ${ }^{14,25,26}$ highlight the consistent roles played by computerised analysis tools and opposition analysis in contemporary team preparation. However, the extent of the systematic use of PA across a broad range of coaching qualification and experience profiles, and a wide range of sports is currently not known.
It is important to identify the perceived barriers to coaches' use of PA in order to understand how best the discipline of PA can be progressed. Time and cost were identified as key issues in several studies ${ }^{11,15,17}$ while knowledge of technology, ${ }^{15}$ and how to integrate PA effectively for novice users were also seen as barriers. ${ }^{16}$ O'Donoghue and Mayes ${ }^{25}$ have highlighted how technology is changing PA practice. The recent proliferation of PA 'apps' and the use of online platforms to share feedback would support this assertion; however, little research exists examining their use in coaching practice. This study seeks to investigate these issues with a long-term view to 'future-proofing' the optimisation of the PA process.

The purpose of this study was therefore to establish the level of engagement with PA among coaches, the profiles and factors associated with coaches using PA and how they integrate it into their coaching practice. It will also investigate the perceived value of PA to coaches and barriers to its use. This PA usage information gathered across a diverse cohort of Irish based coaches will be of value to a number of different stakeholders in the sports performance eco-system, including National Governing Bodies of various sports, coach and PA educators, researchers and practitioners, and commercial enterprises. This research is of particular interest to the Sport Ireland Institute and Sports Institute Northern Ireland to inform decision making around plans for future PA service provision in Irish sport, thus a cohort of Irish coaches was recruited.

\section{Methods}

A questionnaire was devised by three performance analysts with 27 accumulative years' experience in the field. The questionnaire was piloted in a subset of the target population (nine qualified coaches who were also part of a PA Special Interest group). These individuals were chosen because of their knowledge of both the coaching and PA arenas. The questionnaire that was piloted was based on the validated tool used by Wright et al. ${ }^{17}$ (a study based on 46 semi-professional and professional coaches), with minor proposed adaptations to a number of questions for use in a broader coaching context. These proposed adaptations were discussed within the pilot group and some were subsequently disregarded. The data reported here are based exclusively on Wright et al.'s tool, with two additional questions on barriers to use of PA and PA training needs.

The self-administered online questionnaire was hosted on Survey Monkey and took approximately $20 \mathrm{~min}$ to complete. The majority of questions were closed and pre-coded. In order to establish the views of Irish coaches, the survey was distributed to a sample of 12,500 coaches from the Coaching Ireland database 
via email. This is a central database providing access to all coaches who have undertaken coaching qualifications in Ireland, thus a broad cross-section of the coaching population. From a total of 766 responses, 121 incomplete responses were excluded as were 107 responses from coaches who did not meet the inclusion criteria of holding Level 1+ qualifications, leaving 538 responses for analysis. The survey was approved by the ethics committee of the lead author's institution and satisfied the conditions of the Helsinki Declaration.

To facilitate succinct reporting here, the data were broken down into primary outcomes of interest which included (1) profile information (i.e. demographics, coaching experience and qualifications), (2) use and integration of PA, (3) perceived value of PA, (4) barriers to the use of PA. Four questions relating to key performance indicators were omitted from analysis due to perceived confusion around terminology. The ChiSquare test was used to test for association between a range of variables such as coaching qualifications and the proportion of coaches using PA. Mann Whitney U tests were used to compare variables where responses used ordinal scales. A significance level of 0.05 was used for all analyses. Statistical analyses were carried out using SPSS (version 20.0, IBM Corp.).

\section{Results}

\section{Profile of coaches engaged with PA}

The median age range for the group was 40-49 years old and $82 \%$ of the respondents were male. Coaches from 37 sports responded to the survey, 54\% team sports coaches, $46 \%$ individual sports. Seven sports made up $72 \%$ of the cohort, these were: Gaelic Games (27\%), Athletics (15\%), Soccer (9\%), Rowing $(6 \%)$, Hockey (6\%), Rugby (5\%) and Basketball (4\%).

A statistically significant association was observed between the use of PA and increased coaching experience $\left(\chi_{2}^{2}=52.7 P=0.00\right)$; level of coaching qualification $\left(\chi_{6}^{2}=79.7 P=0.00\right)$; level of athlete coached $\left(\chi_{1} 0^{2}=\right.$ $135.9 P=0.00)$; hours per week coaching $\left(\chi_{8}^{2}=90.2\right.$ $P=0.00) ; \quad$ and remuneration Status $\left(\chi_{8}^{2}=59.2\right.$ $P=0.00) \quad$ (Table 1). An examination of the

Table I. Profile of coaches expressed in terms of the performance analysis engagement spectrum.

\begin{tabular}{|c|c|c|c|c|c|}
\hline Variable & Category & $\%$ Total & $\begin{array}{l}\% \text { No formal } \\
\text { analysis }\end{array}$ & $\begin{array}{l}\% \text { Coach as } \\
\text { analyst }\end{array}$ & $\begin{array}{l}\% \text { Coach + analyst } \\
\text { support }\end{array}$ \\
\hline \multirow[t]{4}{*}{ Years coaching } & Less than 5 years & 30 & 20 & 8 & 2 \\
\hline & $6-10$ years & $3 I^{a}$ & $16^{\mathrm{a}}$ & $12^{\mathrm{a}}$ & 3 \\
\hline & $\mid \mathrm{I}-15$ years & 12 & 4 & 6 & $3^{\mathrm{a}}$ \\
\hline & More than 15 years & 27 & 9 & 12 & 6 \\
\hline \multirow{6}{*}{$\begin{array}{l}\text { Highest level of } \\
\text { athlete coached }\end{array}$} & Elite senior & 8 & 1 & II & 29 \\
\hline & Elite age grade & 9 & 5 & 12 & 15 \\
\hline & High performance Senior & 14 & 8 & 19 & $26^{\mathrm{a}}$ \\
\hline & High performance Age grade & 18 & 17 & $23^{\mathrm{a}}$ & 11 \\
\hline & University/school & $12^{\mathrm{a}}$ & 13 & 13 & 6 \\
\hline & Club competing at local level & 38 & $56^{\mathrm{a}}$ & 24 & 13 \\
\hline \multirow[t]{4}{*}{ Coaching qualifications } & NGB Level I & 48 & $32^{\mathrm{a}}$ & 12 & 3 \\
\hline & NGB Level 2 & $33^{\mathrm{a}}$ & 12 & $16^{\mathrm{a}}$ & $5^{\mathrm{a}}$ \\
\hline & NGB Level 3 & 12 & 4 & 7 & 2 \\
\hline & NGB Level 4 & 7 & $\mathrm{I}$ & 3 & 2 \\
\hline \multirow[t]{5}{*}{ Hours/week coaching } & Up to $5 \mathrm{~h}$ per week & 41 & 21 & 11 & 2 \\
\hline & 6-10 h per week & $27^{\mathrm{a}}$ & $13^{\mathrm{a}}$ & $1 I^{\mathrm{a}}$ & 4 \\
\hline & II-I5 h per week & 15 & 4 & 8 & $3^{\mathrm{a}}$ \\
\hline & 16-20 h per week & 7 & 2 & 4 & 1 \\
\hline & More than $20 \mathrm{~h}$ per week & 10 & 3 & 4 & 4 \\
\hline \multirow[t]{4}{*}{ Remuneration status } & Volunteer - Unpaid & $60^{\mathrm{a}}$ & $37^{\mathrm{a}}$ & 19 & 4 \\
\hline & Volunteer with expenses & $\mathrm{II}$ & 3 & $6^{\mathrm{a}}$ & 3 \\
\hline & Part time paid coaching position & 17 & 6 & 7 & $4^{\mathrm{a}}$ \\
\hline & Full time paid coaching position & 12 & 4 & 6 & 3 \\
\hline
\end{tabular}

Note: $N=538$.

${ }^{\mathrm{a}}$ The median value for that cohort. 
demographic factors differentiating coach-as-analysts and those with analyst-support showed the latter group were more experienced, coached more hours per week and worked with more talented athletes.

\section{A spectrum of engagement with PA}

The survey found evidence of a spectrum of coaches' engagement with PA. The spectrum ranges from those coaches who use no formal analysis $(49 \%)$, to those coaches using PA tools to carry out their own analysis $(38 \%)$ and finally to coaches who have access to a performance analyst $(13 \%)$. The latter two groups were labelled coach-as-analyst and coach with analyst-support, respectively highlighting the two differing modes of PA delivery. The range and variation in the use of PA within coaching practices which was evident from the survey suggests a spectrum of PA engagement with PA from users to non-users. However the findings also highlight another dimension within PA users: the degree to which the use of PA could be said to be highly systematic as seen in professional contexts. The 'length' and 'breadth' of the spectrum is represented in Figure 1. The practices of four coaches who responded to the survey are included as a means of illustrating the breadth of practice which was reported within each cohort.

PA practice among coaches. When asked to provide details of the elements of PA to which they had access, it is apparent (Table 2) that a greater proportion of coaches with analyst-support have access to the core PA elements such as video and edited clips, compared to the coach-as-analyst group. They also have access to an extended range of PA elements, for example, motivational compilations and opposition analysis.

A breakdown of the variety of PA tools coaches used (Figure 2) shows the contrast in PA tools used by the two cohorts. Dartfish was the most popular brand (24\%), followed by SportsCode (13\%); Kinovea (7\%) and Focus X2 (5\%). The use of Qunitic, Nac Sport, Motionview, Longomatch, Cricketstat, and Kandle was also reported. Many coaches used apps in conjunction with other technology (Figure 3). Ubersense and CoachesEye were the most commonly named apps by respondants. A small minority of coaches $(2 \%)$ used sports analysis companies; Opta, Prozone, Winsplits and Crossover to supply data, while $5 \%$ opted for analysis and video sharing platforms Performa Sports, Sprongo and iCoda. Various timing and route tracking tools were identified including Garmin, MapMyRide, videoPeikko, Routegadge, and Freelap. Cycling coaches reported measuring power output using Powertap and SRM power meters.

When asked specifically how often they have access to video post-performance, the findings (Figure 4) highlight a significant difference in video access between those with and without analyst-support $(U=3185.5, P=0)$. The data also demonstrate a general lack of video access for all coaches; only $40 \%$ of

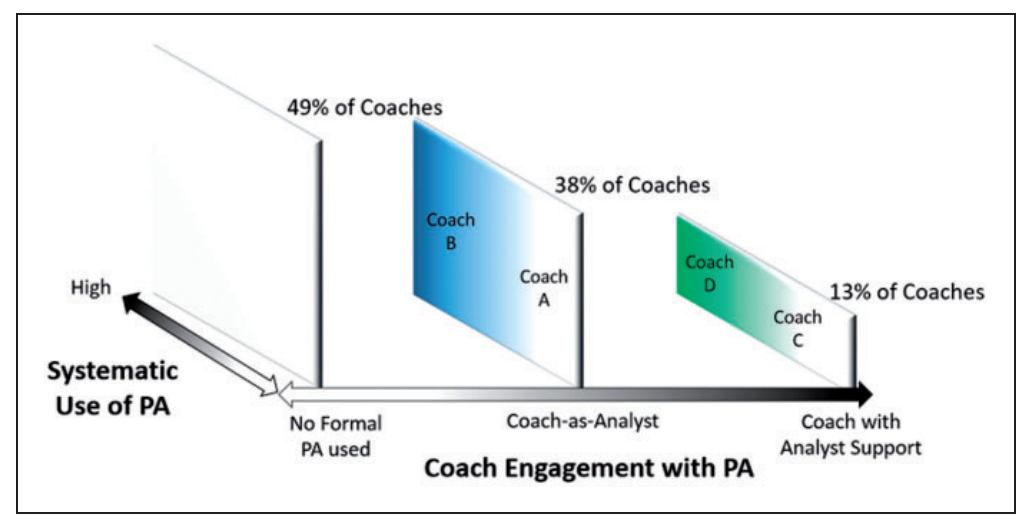

Figure I. Schematic representation of the spectrum of coach engagement with PA with examples illustrating where coaches may place on the spectrum. Coach A - Basketball coach-as-analyst: coaches club athletes, I h spent analysing per performance, PA does not inform training, uses hand notation, never has access to video, feels PA is not important in influencing behaviour change. Coach B Field hockey coach-as-analyst: coaches elite age grade athletes, $6 \mathrm{~h}+$ spent analysing per performance, PA regularly informs training, uses analysis software \& Apps, regular access to video, uses opposition analysis and motivational compilations. Coach $\mathrm{C}-\mathrm{Rowing}$ coach with analyst support: coaches elite senior athletes, $2 \mathrm{~h}+$ spent analysing per performance, PA rarely informs training, uses analysis software \& Apps, rarely has access to video, feels PA is essential in influencing behaviour change. Coach D - Hurling coach with analyst support: coaches high performance senior athletes, $6 \mathrm{~h}+$ analysing per performance, PA regularly informs training, uses analysis software \& Apps, regular access to video, uses opposition analysis and motivational compilations. PA: performance analysis. 
Table 2. PA elements to which coaches using PA had access.

\begin{tabular}{|c|c|c|c|}
\hline Element of PA & $\begin{array}{l}\% \text { Coach } \\
\text { as analyst }\end{array}$ & $\begin{array}{l}\% \text { Coach }+ \\
\text { analyst support }\end{array}$ & $P$ value \\
\hline View video of full game & 37 & 68 & 0.00 \\
\hline Use video clips to feedback to team/individuals/units of the team & 51 & 83 & 0.00 \\
\hline View edited clips from the game/performance & 25 & 58 & 0.00 \\
\hline View edited clips of specific athletes & 20 & 46 & 0.00 \\
\hline Use video clips to feedback to other coaches or support staff members & 26 & 51 & 0.00 \\
\hline View video of opposition before a game/performance & 19 & 47 & 0.00 \\
\hline Quantitative match data i.e. match statistics & 44 & 57 & \\
\hline Motivational compilation & 22 & 40 & $<0.002$ \\
\hline Live coding/tagging analysis during performance & 9 & 29 & 0.00 \\
\hline Technical analysis of specific actions & 44 & 47 & \\
\hline Multiple angles of same performance & II & 14 & \\
\hline Feedback shortly after performance (within $24 \mathrm{~h}$ ) & 31 & 36 & \\
\hline Half time feedback using video footage & 4 & II & $<0.015$ \\
\hline Half time feedback using match statistics & 22 & 38 & $<0.008$ \\
\hline Not applicable & 9 & I & \\
\hline
\end{tabular}

Note: $N=272 ; 72$ coaches with analyst support. $P$ values relate to Chi-Squared test. PA: performance analysis.

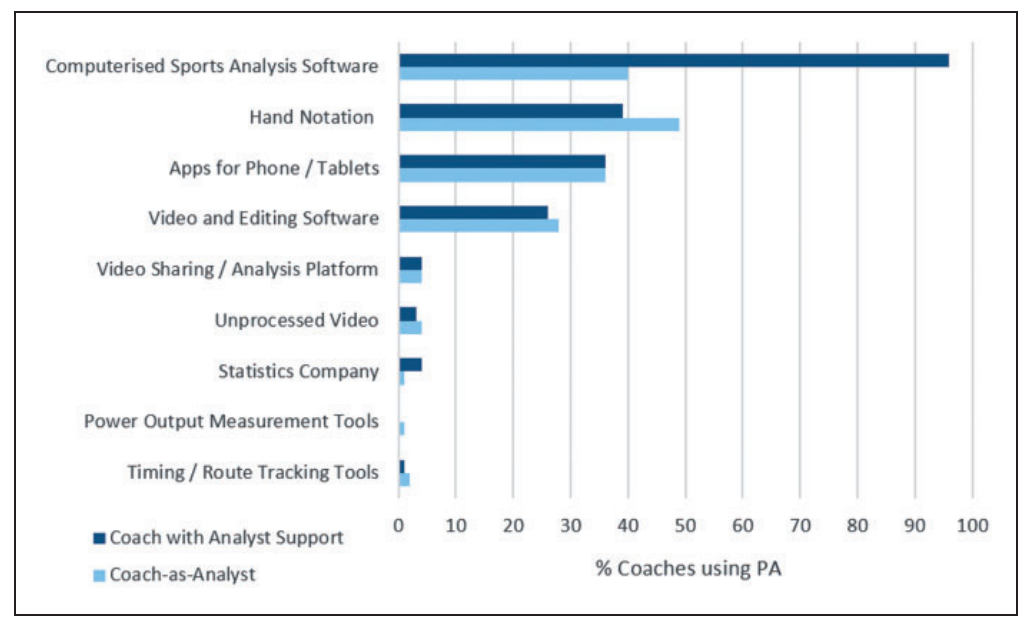

Figure 2. Range of performance analysis tools used by coaches with and without access to an analyst. $N=272,72$ coaches with analyst support.

coach-as-analysts have regular access to video, rising to $71 \%$ of coaches using an analyst.

How PA information is received and interpreted is critical to its potential impact. Coaches with analystsupport received significantly more information $\left(\chi_{4}^{2}=57.2 P=0\right.$; Figure 5) than coach-as-analysts and had more access to edited video and combinations of video and statistical feedback. These coaches also spent significantly more time reviewing the information provided than coaches without analyst-support ( $U=4730.5, P=0$; Figure 5).
Several of the survey questions addressed the integration of PA into the coaching process in terms of its role in planning and influencing tactical and technical strategies (Table 3). The responses show PA is used mostly for short term planning by coaches and no significant differences exist between those with and without analyst-support. Both groups felt PA was important in affecting technical or tactical changes in athletes, with $77 \%$ of coach-as-analysts and $90 \%$ of coaches with analyst-support stating it was essential or very influential. 
Coaches were asked about the extent to which the elements of PA they used inform the content of their training sessions (Figure 6). Coaches with analystsupport used PA information more often to inform the content of their training.

\section{Value of PA to coaches}

When asked to place a value on the use of PA and the services of a performance analyst, the majority of coaches valued PA as important to essential (Figure 7).

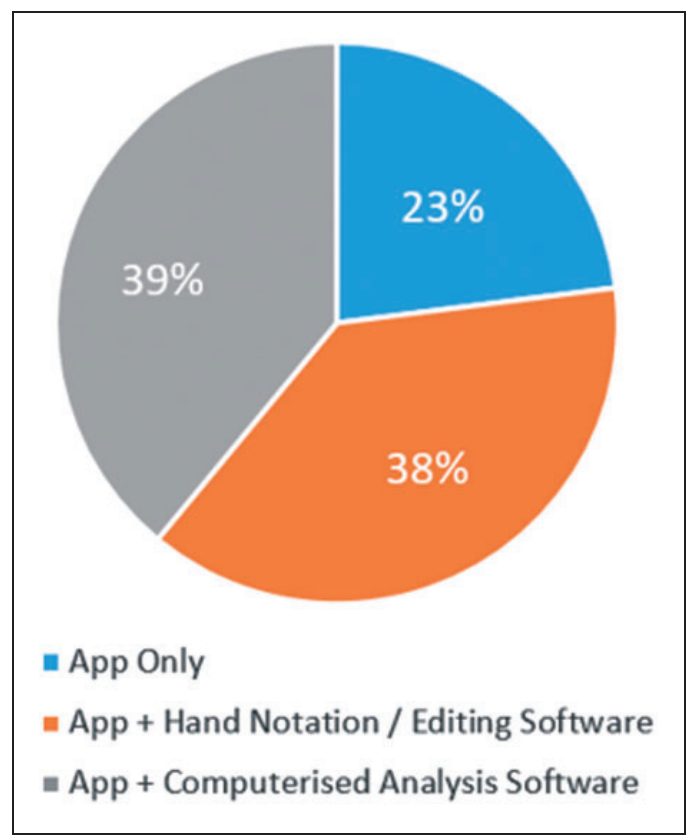

Figure 3. Coaches' use of apps in conjunction with other technology. $\mathrm{N}=98$
However this was not matched by their assessment of how their sporting organisations valued PA, based on the coaches' observed commitment of money and resources. When asked if they would like to use more PA within their coaching, $94 \%$ of coaches said yes.

\section{Barriers to using PA}

The entire cohort of coaches recorded the factors which they felt were barriers to using PA (Table 4). Knowledge (32\%) was the key issue identified by coaches using no formal PA. Cost (of software, hardware and personnel) and time taken to analyse/interpret information were the other key issues highlighted by non-PA users and both of these factors increased significantly for coaches using PA. Finally all coaches were asked if they would like training on how to integrate PA effectively into their coaching and the majority answered yes $(86 \%)$.

\section{Discussion}

\section{Spectrum of PA engagement}

The purpose of this research was to gain an insight into the level of engagement of a broad cross-section of coaches with PA, and how they integrated it into their practice. Additionally, we sought to assess the perceived value of PA and identify barriers to its use. The findings demonstrate the existence of a spectrum of coaches' engagement with PA. The spectrum ranges from those who use no formal PA $(49 \%)$, to those who do their own analysis - 'coach-as-analysts' (38\%) and coaches who engage the support of a performance analyst $(13 \%)$. There is evidence of a range of PA practices within each user group, for example some

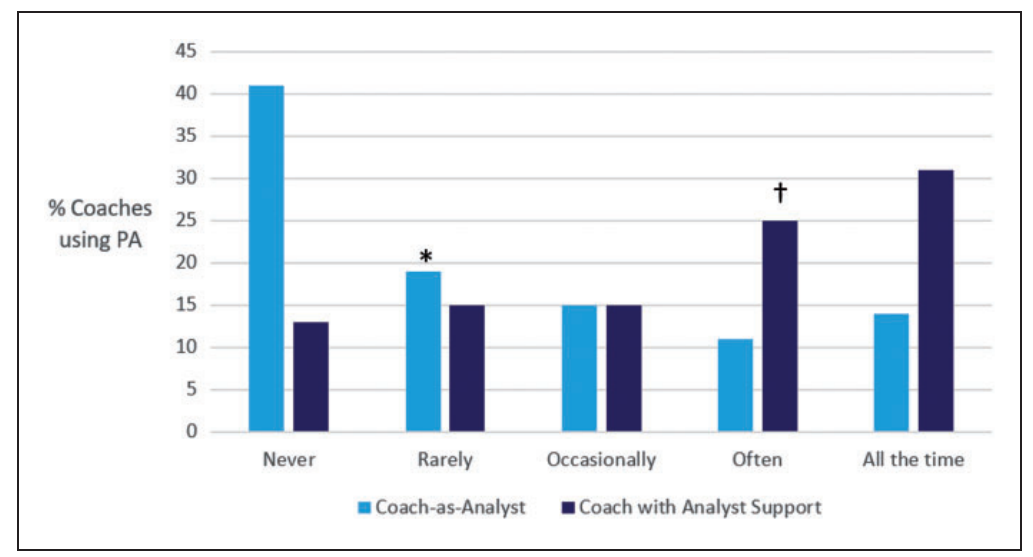

Figure 4. The frequency of post-performance video provision to coaches using performance analysis with and without an analyst (rarely, 2-3 times per year; occasionally, I-2 times per month; often, after most performances). $\mathrm{N}=272,72$ coaches with access to an analyst. * Indicates median response of coach-analysts. $\dagger$ Indicates median response of coaches with analysis support. 


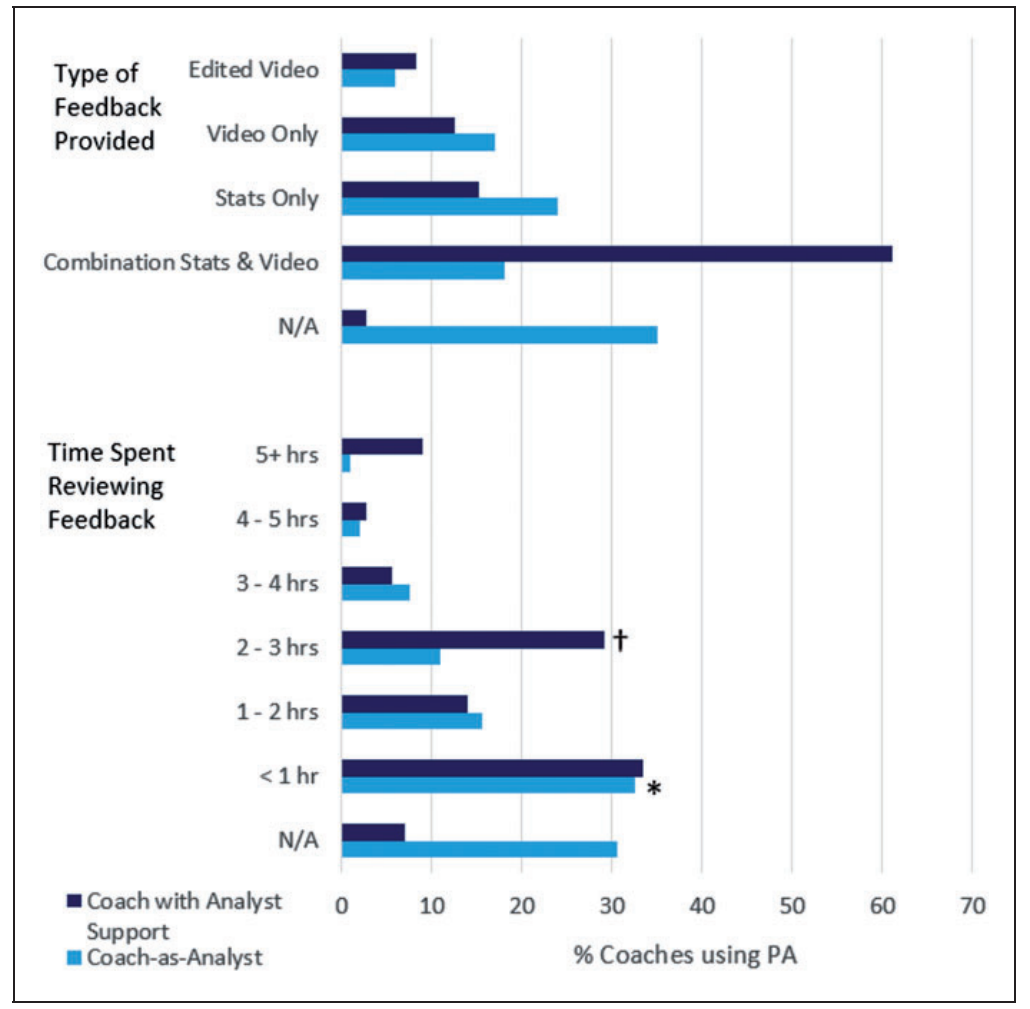

Figure 5. The type of feedback provided to coaches doing performance analysis with and without an analyst and the time they spent reviewing it. $\mathrm{N}=272,72$ coaches with analyst support. * Indicates median response of coach-analysts. $\dagger$ Indicates median response of coaches with analyst support.

Table 3. Integration of PA into the coaching process - responses of coaches who use PA.

\begin{tabular}{|c|c|c|c|}
\hline Question & Response & $\begin{array}{l}\% \text { Coach } \\
\text { as analyst }\end{array}$ & $\begin{array}{l}\% \text { Coaches }+ \\
\text { analyst support }\end{array}$ \\
\hline \multirow{6}{*}{$\begin{array}{l}\text { Does the PA information } \\
\text { you receive inform } \\
\text { your planning? }\end{array}$} & Short term planning & 60 & 61 \\
\hline & Medium term planning & 50 & 47 \\
\hline & Long term planning & 36 & 40 \\
\hline & $\begin{array}{l}\text { Change your strategy for the next } \\
\text { match/performance }\end{array}$ & 34 & 38 \\
\hline & $\begin{array}{l}\text { Influence your training plans } \\
\text { for the next week }\end{array}$ & 61 & 67 \\
\hline & Not applicable & 6 & 1 \\
\hline \multirow{6}{*}{$\begin{array}{l}\text { How influential is PA information } \\
\text { in developing/introducing changes } \\
\text { in playing style/tactics/individual } \\
\text { technique? }\end{array}$} & Essential & 44 & 49 \\
\hline & Very & $33^{\mathrm{a}}$ & $4 I^{\mathrm{a}}$ \\
\hline & Fairly & 16 & 10 \\
\hline & Not very & 6 & 0 \\
\hline & Not at all & 6 & 0 \\
\hline & Not applicable & 3 & 0 \\
\hline
\end{tabular}

Note: $N=272 ; 72$ coaches with analyst support.

PA: performance analysis.

${ }^{\mathrm{a}}$ The median response. 


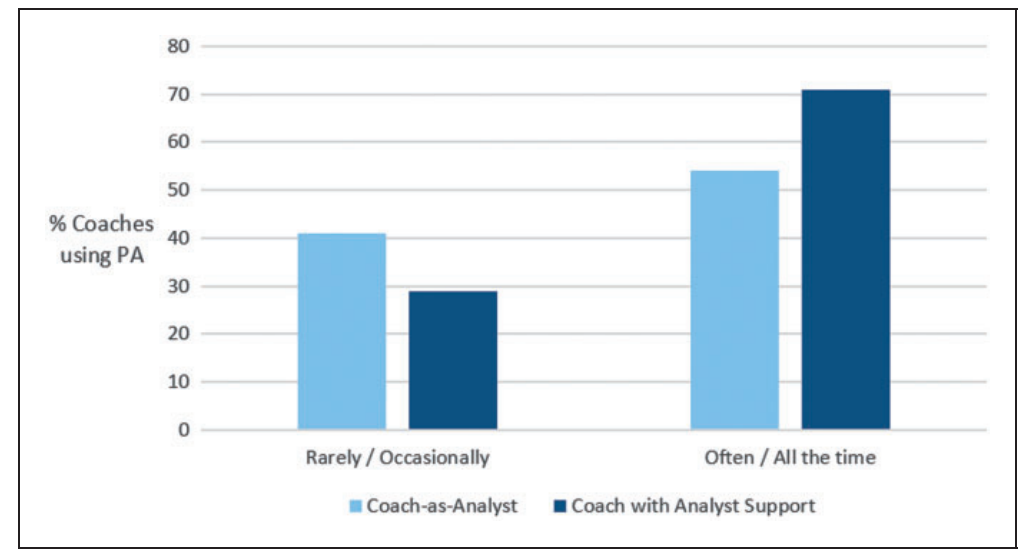

Figure 6. Frequency that performance analysis informs the content of training sessions for coaches using performance analysis with and without analysis support. $\mathrm{N}=272,72$ coaches with analyst support. (rarely, 2-3 times per season; occasionally, 4-6 times per year; often, 4-5 times per month).

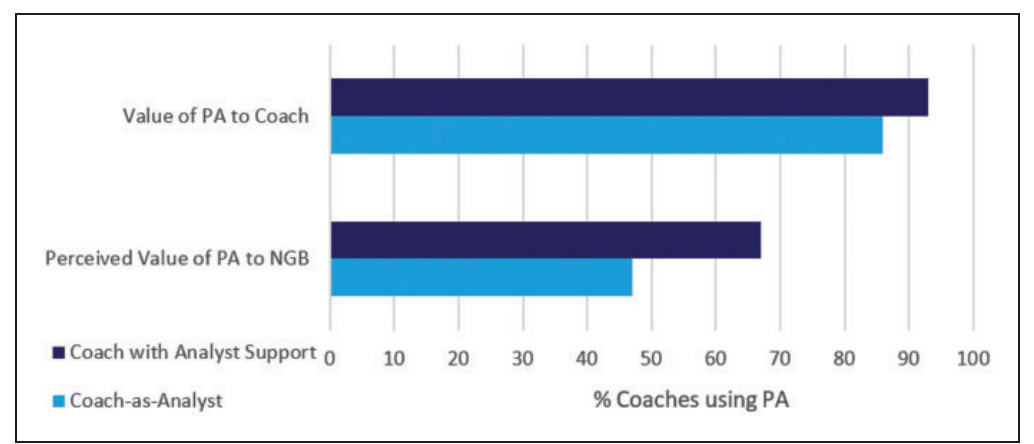

Figure 7. The percentage of coaches rating performance analysis as important to essential, to them and their NGB N=272.

coach-as-analysts spend many hours analysing and consistently using PA to inform training, while some coaches with analyst-support rarely integrate PA findings with training. Thus, we submit the concept of a spectrum or continuum of engagement. This concept is supported by smaller scale studies such as Wright et al., ${ }^{17}$ whose survey found that only $32 \%$ had access to a performance analyst. Sarmento, Bradley and Travassos ${ }^{27}$ recent study of six elite futsal coaches found only one with a performance analyst. The others were using data collected by a member of their technical staff specialising in PA (i.e. coach-as-analyst). As the first large scale survey of a broad mix of elite and participation coaches, the findings establish a benchmark for future assessment of coach use of PA in Ireland and beyond.

\section{Profile of coaches}

We have identified a number of factors which differentiate where a coach will place on the spectrum. The key indicators are level of qualification, access to resources, experience and the level of performer coached. Coaches using no formal analysis are typically Level 1 qualified with less than 10 years' experience. They coach at club level for less than $10 \mathrm{~h}$ a week and do not receive any payment. The statistically significant median profile for the 'coach-as-analyst' group is similar however they are likely to receive expenses, be qualified at Level 2 and to be coaching high performance age grade athletes. At the end of the spectrum, coaches with analyst-support are typically Level $2+$ qualified, have $10+$ years' experience, coach high performance senior or elite athletes and hold full or part time roles.

The Level 2 NGB qualification was a key distinguisher between those coaches using and not using PA. For performance coaches, this may be reflective of a juncture in their career where they have gained sufficient experience to have access to more talented athletes and increased resources. The identification of the Level 2 award as a threshold is important to coach education designers as it provides an opportunity to target material and support to the development of the necessary PA expertise at this level. It also defines the target audience for those designing and delivering 
Table 4. Barriers to expanding and progressing their use of PA - responses from all coaches.

\begin{tabular}{|c|c|c|c|c|c|}
\hline Theme & Barrier & $\begin{array}{l}\% \text { Coaches no } \\
\text { formal analysis }\end{array}$ & $\begin{array}{l}\% \text { coach- } \\
\text { as-analyst }\end{array}$ & $\begin{array}{l}\% \text { Coaches }+ \\
\text { analyst support }\end{array}$ & $P$ value \\
\hline Knowledge & I would like to know more in order to progress ${ }^{a}$ & 32 & 15 & 13 & 0.00 \\
\hline \multirow[t]{3}{*}{ Cost } & Cost of software ${ }^{a}$ & 23 & 58 & 70 & 0.00 \\
\hline & Cost of hardware ${ }^{a}$ & 17 & 40 & 52 & 0.00 \\
\hline & Cost of personnel ${ }^{a}$ & 12 & 39 & 40 & 0.00 \\
\hline \multirow[t]{3}{*}{ Time } & $\begin{array}{l}\text { Time taken to complete analysis (tasks too } \\
\text { long/arduous) }^{\mathrm{a}}\end{array}$ & 12 & 31 & 25 & $<0.001$ \\
\hline & $\begin{array}{l}\text { Lack of time available to interpret and analyse } \\
\text { information }\end{array}$ & 17 & 30 & 29 & $<0.001$ \\
\hline & $\begin{array}{l}\text { Time lost from training/practice to feed back } \\
\text { the information }\end{array}$ & 8 & 16 & 13 & \\
\hline \multirow[t]{3}{*}{ Personnel issues } & Can't find someone to do it & 9 & 15 & 15 & \\
\hline & $\begin{array}{l}\text { Players' responsiveness to video has been } \\
\text { overly negative }^{\mathrm{a}}\end{array}$ & 0 & 6 & 7 & $<0.001$ \\
\hline & $\begin{array}{l}\text { Other members of the support teams } \\
\text { responsiveness to feedback }\end{array}$ & 3 & 4 & 1 & \\
\hline \multirow[t]{2}{*}{ Other resources } & Availability of equipment i.e. laptop, PC's, screen ${ }^{a}$ & 13 & 26 & 22 & $<0.002$ \\
\hline & $\begin{array}{l}\text { Availability of appropriate room/space to hold } \\
\text { feedback sessions }{ }^{\mathrm{a}}\end{array}$ & 2 & 7 & 13 & $<0.001$ \\
\hline \multirow{5}{*}{$\begin{array}{l}\text { Value/nature of } \\
\text { information }\end{array}$} & Usability of the information provided & 3 & 8 & I & \\
\hline & Reliability of the information provided & 0 & 3 & 3 & \\
\hline & Concern over information overload ${ }^{\mathrm{a}}$ & 6 & 13 & 18 & $<0.005$ \\
\hline & Concern over analysis as a distraction & 4 & 10 & 6 & \\
\hline & Don't consider that the analysis adds value & 1 & 0 & 0 & \\
\hline N/A & Not applicable & 40 & 4 & 0 & \\
\hline
\end{tabular}

Note: $N=538$. No PA 266 , coach as analyst 200 , coaches with analyst support $72 . P$ values relate to Chi-Squared test. PA: performance analysis.

${ }^{\text {a }}$ Statistical significance.

continuing professional development of coaches in the PA field.

\section{PA practice among Irish coaches: use and integration of PA}

A novel characteristic of this study is the comparison of the PA practices of coaches with and without analystsupport. Comparing their practices to those identified in the literature as being indicative of the systematic use of PA in professional settings ${ }^{14,17,26}$ allows us evaluate to some extent, the nature of PA use within the two cohorts that emerged in our study. When coaches have access to analyst-support, the volume of core PA elements (edited video, statistical feedback) is increased to a level similar to those of the professional coaches in Wright et al.'s ${ }^{17}$ survey. The coach-as-analyst cohort had significantly less access to opposition analyses and motivational compilations, potentially due to the time taken to prepare this type of feedback vs. the lack of time that group identified as a key barrier later in the survey.
Video plays a fundamental role in PA practice in three ways. It acts as the gold standard in verifying the reliability of any data collected. ${ }^{28}$ Video allows coaches and athletes figure out 'why' and 'how' performance occurred through qualitative analysis ${ }^{2}$ and it is often integral to feeding information back to athletes. ${ }^{29}$ Regular access to video is suggestive of coaches using PA systematically. The fact that only $40 \%$ of our coach-as-analysts cohort receive video regularly suggests that their PA use in general is not systematic. As $71 \%$ of coaches with analyst-support have regular access to video, a significant distinction is evident between the two cohorts. The majority $(93 \%)$ of elite coaches surveyed by Wright et al., ${ }^{17}$ and $73 \%$ of the US swim coaches responding to Mooney and colleagues ${ }^{15}$ reported regular access to video however it is not known from these studies which coaches had access to formal analyst-support.

Computerised sports analysis software is acknowledged as the most efficient method of observing performance, ${ }^{30}$ and its use is common practice in 
professional PA systems. ${ }^{12}$ The gap in use of computerised analysis software between coach-as-analyst $(40 \%)$ and coaches with analyst-support $(96 \%)$, is further evidence of differing PA practices between the cohorts. Cost is a critical factor in this, as indicated later, and this is substantiated by the predominance of hand notation and free video editing software tools. The move towards mobile computing ${ }^{31}$ is reflected in the study as $36 \%$ of coaches used 'app' based technology and 5\% accessed the power of multi-faceted web based platforms, for example, Sprongo. In general, the use of 'apps' was not significantly linked to any profile factor, cohort of the spectrum, or major sports grouping, perhaps indicating their versatility and universal appeal.

The use of the term 'analyst-support' to describe coaches with access to an analyst was carefully chosen. The evidence reveals that many of the coachas-analyst cohort $(65 \%)$ have access to some feedback in the form of video or statistics which was not provided by an analyst; one basketball coach reported that the match video was taken by a parent of an athlete. Perhaps this falls under the broader umbrella of 'PA support', a term increasingly prevalent in literature. ${ }^{25,26}$ The phrase, PA support, is currently undefined and could mean anything from an injured player notating stats, to an analyst immersed in managing and delivering PA information and feedback within a high performance team. As previously identified by Carling and colleagues, ${ }^{32}$ there is a need to define what 'PA support' means from its simplest function to the most complex roles of applied performance analysts in various high performance environments.

Time spent reviewing video and statistical feedback is another potential indicator of systematic analysis and this study found a significant difference between the coaches with and without analyst-support. The coach-as-analysts had considerably less material to review and spent less than an hour doing so. Coaches with analyst-support more often had access to quantitative information combined with video (61\%) and spent a median 3-4 h reviewing it. A complex qualitative analysis of the 'why and how' of performance takes time ${ }^{2}$ and our findings suggest that this process is in place for the coaches with analystsupport, as illustrated in recent case studies. ${ }^{6,9}$ The support of an analyst may also potentially enhance how messages are received by athletes as Nelson et al., suggest that most respect is afforded to coaches who "Invested considerable amounts of time and energy into the development of slick and well-organised presentations that included edited video clips and had clear links to the objectives of training sessions"7 (p.26). From the demographic data it is clear that this cohort of coaches with analyst-support are more likely to be in part or full-time paid coaching roles and thus may have more time to invest in the process.

Another potential indicator of systematic use of PA is its role in planning. ${ }^{33}$ Our findings indicate that PA makes some impact on planning; however, this is mostly short-term. Changes in performance are generally affected through strategies implemented in practice sessions. ${ }^{30}$ There appears to be a conflict between how influential coaches claim PA is on changing performance, and how much they actually use it to inform training sessions. Although $77 \%$ of coach-as-analysts felt it was very important to essential to changing style or technique, just over half used PA regularly to inform training, This may be indicative of occasional use of PA and when used it is influential e.g. at specific times of the season or preparation for particularly important events. Alternatively, it may be the case that coaches do not have sufficient opportunity to analyse data and fully recognise the implications of the information. Where access to a greater volume of information is evident in the coaches with analyst-support cohort, $70 \%$ of coaches used PA regularly to inform the content of training and $91 \%$ felt it very influential/ essential to affecting change. This suggests that coaches with analyst-support are integrating PA in a more systematic fashion into their practice than their coach-as-analyst peers.

\section{Value of PA to coaches}

The vast majority of coaches using PA $(86 \%)$ valued it as 'important to essential' to their practice. The finding is consistent with the positive ratings and assessments of PA by coaches in similar investigations ${ }^{10,11,16,17}$ thus building on the body of evidence indicating that coaches value PA as a key tool in their practice. Indeed $94 \%$ of coaches using PA indicated that they would like to use more. There was a considerable difference in how coaches valued PA and their estimation of how their organisations valued it. Given that these findings are coaches' perception of administrators' attitude towards $\mathrm{PA}$, further research is warranted to explore the actual opinions of sports administrators. However, these findings pose an interesting challenge for PA as a discipline when approximately $40 \%$ of coaches felt their organisation both in Ireland and the $\mathrm{UK}^{17}$ view PA as 'not very important' in terms of how it is resourced. Lack of knowledge of how PA can be integrated into coaching is identified as a barrier to PA use in this study. This lack of knowledge potentially extends to sports administrators and may be reflective of the difficulty PA has in expressing or promoting its value as a support service. Indeed it has been written that PA, 'defies accurate, or unambiguous definition". ${ }^{34}$ Its interdisciplinary 
nature means it can be challenging to define simply what PA is, and indeed how it can definitively add value to coaches and athletes.

\section{Barriers to use of PA}

The numbers responding to this survey confirmed anecdotal evidence of considerable interest in PA among Irish coaches, thus an investigation into the barriers to using or expanding use of PA was an important aspect of the study. Findings reveal the principal barrier for those using no formal analysis is knowledge, whereas cost (of software, hardware and personnel) and time are more significant barriers for coaches who are actually using PA. This research builds on previous findings which identified these factors as barriers impacting PA practices. ${ }^{15,17}$ It is apparent that the analysis process constructed by a coach is strongly influenced by their resources and skill set. While it is challenging to address cost barriers, it may be worthwhile for coaches to invest time in upskilling to maximise the efficiency of their analysis processes.

The majority of coaches $(86 \%)$ indicated they would like training on how to integrate PA effectively into their coaching, suggesting considerable demand for coach education in the discipline. However there is a disconnect between their responses when asked if they want training ( $92 \%$ coaches with analyst-support) and if they felt knowledge was a barrier to their use of PA (13\% coaches with analyst-support). This gap may be reflective of coaches who genuinely want to learn more but when training is offered do not prioritise it as they feel they have sufficient knowledge to get by. It highlights the importance of building high quality PA content into existing formal coaching qualifications and the provision of 'bite-sized' learning opportunities in PA as continuing professional development for coaches.

\section{Limitations}

Surveys are a cost-efficient research tool that facilitate the collection of a greater breadth of information than is possible with other research methods. They are an excellent precursor for planning further, more targeted studies. The data generated from our survey achieved both of these goals, but we are cognisant of some of the limitations inherent in our study. Firstly, we can assume that only those respondents who care about PA are likely to have taken the time to participate in the study, thus creating a responder bias. We know nothing of why the non-responders chose not participate. Secondly, many of the questions were closedended which requires us to question the validity of the responses i.e. it is possible that not all participants were met with the answer that was relevant to them.
Additionally, the two questions that we added to the Wright et al., ${ }^{17}$ tool on barriers to PA use and PA training needs were piloted with a small group of coaches, but were not explicitly validated. Finally, the way that people rank categories such as 'very important' vs. 'important' can be rather subjective. While we acknowledge these limitations, we feel that they are offset by the size of our cohort and the fact that we are knowingly presenting a 'snap-shot' of information at a moment in time, and have been careful not to attribute causal relationships within our data. Further investigations informed by this study are required to tease out the interesting associations that we have observed to date.

\section{Conclusions and future directions}

The results of this survey show a spectrum of engagement with PA in a broad population of coaches. Almost half of coaches used no formal PA, citing knowledge, time and cost as the main barriers. It is not known whether they would use PA if these barriers were removed. Within PA users, two groups were identified, those with and without access to analyst-support. Many of the coaches with analyst-support incorporated practices consistent with the systematic integration of PA in professional contexts. This was significantly different from the practices of 'coach-as-analysts' who generally did not have regular access to video or computerised analysis software, spent less time analysing and did not use PA to inform training on a regular basis, suggesting sub-optimal use of PA. Given that this group accounted for three quarters of all PA users, further investigation into strategies to maximise the PA practices of coach-as-analysts is warranted.

The findings have implications for coach educators by identifying the formal Level 2 NGB qualification as a threshold for the use of PA. This should encourage coach education designers to target material and support for the development of PA expertise that caters for the potentially differing needs of both cohorts of users. It is possible that coach-as-analysts may need more practical and technical support to physically collect and deliver valid and reliable performance information in the most efficient way possible. Coaches engaging analyst-support may need assistance in defining roles, building relationships, developing appropriate analysis systems, interpreting information and directing feedback. The key point is that the analysis process will be different for coaches at different points on the spectrum. Research is warranted to identify the tasks, relationships and skill set required for a coach to deliver PA effectively alone or in collaboration with an analyst. Further investigation into the applied interface of coaches and analysts may assist in providing 
conceptual clarity which is currently lacking. ${ }^{32}$ If performance analysts are considered to be part of the sports science service, it follows that their work should be based upon a professional framework. Research to examine an 'analysis process,' the factors which influence it, how it is intertwined with the coaching process and how it is supported by sports administrators would be informative.

\section{Acknowledgements}

The authors wish to acknowledge staff in Coaching Ireland for facilitating the distribution of this survey.

\section{Declaration of Conflicting Interests}

The author(s) declared no potential conflicts of interest with respect to the research, authorship and/or publication of this article.

\section{Funding}

The author(s) received no financial support for the research, authorship and/or publication of this article.

\section{References}

1. Franks I, Goodman D and Miller G. Analysis of performance: qualitative or quantitative. Sci Period Res Technol Sport 1983; March: 1-8.

2. O'Donoghue PG. An introduction to performance analysis of sport. London: Routledge, 2015.

3. Robertson K. Observation, analysis and video. Leeds: The National Coaching Foundation, 1999.

4. Collins DJ, Trower J and Curickshank A. Coaching high performance athletes and the high performance team. In: Sotiriadou P and De Bosscher V (eds) Managing high performance sport. London: Routledge, 2013, pp.205-220.

5. Groom R and Nelson L. The application of video-based performance analysis in the coaching process. In: Protrac P, Gilbert W and Denison J (eds) Routledge handbook of sports coaching. London: Routledge, 2013, pp.96-105.

6. Groom R, Cushion CJ and Nelson LJ. Analysing coachathlete 'talk in interaction'within the delivery of videobased performance feedback in elite youth soccer. Qual Res Sport Exerc Health 2012; 4: 439-458.

7. Nelson LJ, Potrac P and Groom R. Receiving videobased feedback in elite ice-hockey: a player's perspective. Sport Educ Soc 2014; 19: 19-40.

8. Taylor WG, Potrac P, Nelson LJ, et al. An elite hockey player's experiences of video-based coaching: a poststructuralist reading. Int Rev Sociol Sport 2015; 52: 112-125.

9. Booroff M, Nelson L and Potrac P. A coach's political use of video-based feedback: a case study in elite-level academy soccer. J Sports Sci 2016; 34: 116-124.

10. Groom R and Cushion CJ. Using of video based coaching with players: a case study. Int J Perform Anal Sport 2005; 5: 40-46.

11. Blaze A, Atkinson G, Harwood C, et al. Prevalence and perceptions of performance analysis in the English
Premier Association Football League. In: Performance analysis of sport $V$. Cardiff: Centre for Performance Analysis, University of Wales Institute, 2004, pp.79-83.

12. Wright C, Atkins S, Jones B, et al. The role of performance analysts within the coaching process: Performance Analysts Survey 'The role of performance analysts in elite football club settings.'. Int J Perform Anal Sport 2014; 13: 240-261.

13. Reeves MJ and Roberts SJ. Perceptions of performance analysis in elite youth football. Int J Perform Anal Sport 2013; 13: 200-211.

14. Francis $\mathbf{J}$ and Jones G. Elite rugby union players perceptions of performance analysis. Int J Perform Anal Sport 2014; 14: 188-207.

15. Mooney R, Corley G, Godfrey A, et al. Analysis of swimming performance: perceptions and practices of USbased swimming coaches. J Sports Sci 2015; 34(11): 1-9.

16. Butterworth AD, Turner DJ and Johnstone JA. Coaches' perceptions of the potential use of performance analysis in badminton. Int $J$ Perform Anal Sport 2012; 12: 452-467.

17. Wright C, Atkins S and Jones B. An analysis of elite coaches' engagement with performance analysis services (match, notational analysis and technique analysis). Int $J$ Perform Anal Sport 2012; 12: 436-451.

18. Jenkins RE, Morgan L and O’Donoghue P. A case study into the effectiveness of computerised match analysis and motivational videos within the coaching of a league netball team. Int J Perform Anal Sport 2007; 7: 59-80.

19. Martin D, Cassidy D and O'Donoghue P The effectiveness of performance analysis in elite Gaelic football. World Congress of Performance Analysis of Sport, 2004.

20. O'Donoghue PG. Research methods for sports performance analysis. New York; London: Routledge, 2010.

21. Groom R, Cushion C and Nelson L. The delivery of video-based performance analysis by England Youth Soccer Coaches: towards a grounded theory. J Appl Sport Psychol 2011; 23: 16-32.

22. Booroff M, Nelson L and Potrac P. A coach's political use of video-based feedback: a case study in elite-level academy soccer. J Sports Sci 2016; 34: 116-124.

23. Bampouras TM, Cronin C and Miller PK. Performance analytic processes in elite sport practice: an exploratory investigation of the perspectives of a sport scientist, coach and athlete. Int J Perform Anal Sport 2012; 12: 468-483.

24. McArdle S, Martin D, Lennon A, et al. Exploring debriefing in sports: a qualitative perspective. $J$ Appl Sport Psychol 2010; 22: 320-332.

25. O'Donoghue PG and Mayes A. Performance analysis, feedback and communication in coaching. In: McGarry T, O'Donoghue PG and Sampaio J (eds) Routledge handbook of sports performance analysis. London: Routledge, 2013, pp.155-164.

26. Wright C, Carling C and Collins D. The wider context of performance analysis and it application in the football coaching process. Int J Perform Anal Sport 2014; 14 : 709-733.

27. Sarmento H, Bradley $P$ and Travassos B. The transition from match analysis to intervention: optimising the 
coaching process in elite futsal. Int J Perform Anal Sport 2015; 15: 471-488.

28. James N, Taylor $\mathbf{J}$ and Stanley S. Reliability procedures for categorical data in performance analysis. Int $J$ Perform Anal Sport 2007; 7: 1-11.

29. Maslovat D and Franks IM. The importance of feedback to performance. In: Hughes $\mathrm{M}$ and Franks IM (eds) Essentials of performance analysis in sport, 2nd ed. London: Routledge, 2015, pp.11-17.

30. Hughes M. Notational analysis for coaches. In: Jones RL, Hughes $\mathrm{M}$ and Kingston K (eds) An introduction to sports coaching. London: Routledge, 2008, pp.101-113.
31. Clark $\mathbf{J}$ and Kerski J. Using geotechnology tools in sports coaching. In: Nash C (ed.) Practical sports coaching. London: Routledge, 2015, pp.277-308.

32. Carling C, Wright C, Nelson LJ, et al. Comment on 'Performance analysis in football: a critical review and implications for future research'. J Sports Sci 2014; 32: $2-7$.

33. Lyle J. Sports coaching concepts. London: Routledge, 2002.

34. Sampaio J, McGarry $\mathrm{T}$ and OD PG. Introduction. In: McGarry T, O'Donoghue PG and Sampaio J (eds) Routledge handbook of sports performance analysis. London: Routledge, 2013, pp.1-3. 